\title{
Naar een meerstemmig perspectief op het Nederlandse slavernijverleden
}

\author{
Miguel Heilbron ${ }^{*}$
}

De manier waarop Nederland omgaat met het eigen slavernijverleden is in ontwikkeling, maar nog lang niet evenwichtig. In het publieke debat zijn koloniale beeldvorming en koloniale perspectieven uit het verleden nog steeds dominant. Het blijkt nog steeds vaak de norm om 'trots' en 'positief' terug te kijken op de kolonisator Nederland en op historische figuren die handelden in tot slaaf gemaakte mensen of deze mensen 'bezaten'.

Al decennialang strijden met name zwarte mensen, in Nederland en elders, tegen dominante 'witte', koloniale perspectieven en voor de erkenning van perspectieven van zwarte mensen. De laatste decennia krijgen deze 'zwarte' perspectieven langzaamaan meer voet aan de grond. Toch is de erfenis van koloniale beelden en structuren nog steeds zeer aanwezig en is de dominantie van het witte perspectief nog steeds groot.

Dit artikel bespreekt de strijd voor erkenning van perspectieven van zwarte mensen op de geschiedenis van de trans-Atlantische slavernij, in de Nederlandse context. In wat volgt beschrijf ik allereerst wat met name verschillende kritische zwarte auteurs al eerder beschreven. Ik refereer aan het werk van slechts enkele auteurs, maar er zijn nog veel meer voorbeelden. Hierbij put ik uit een selectie van stukken die onderdeel zijn van de collecties uit The Black Archives.

The Black Archives omvat verschillende boekencollecties, archieven en artefacten die het nalatenschap zijn van zwarte schrijvers, wetenschappers en activisten. Naast collecties afkomstig van individuen beheert het initiatief ook een groot deel van de archieven van Vereniging Ons Suriname, de oudste zelforganisatie van Surinamers in Nederland, die sinds 1919 bestaat. The Black Archives is daarnaast zelf ook een voorbeeld van een nieuwe organisatie die zich inzet voor erkenning van en aandacht voor perspectieven van zwarte mensen. Ten slotte roep ik aan het einde van dit artikel individuen, organisaties, overheden en andere actoren op bij te dragen aan de maatschappelijke transitie vanuit de dominantie van een oud, eenzijdig, koloniaal perspectief, richting een meer gebalanceerd meerstemmig perspectief.

* Miguel Heilbron, MSc, is ontwikkelingseconoom en een van de oprichters van The Black Archives. Ook werkt hij als conceptontwikkelaar en strategisch en creatief adviseur. Met slavernij-instituut NiNSee ontwikkelde hij het concept van de sinds 2016 jaarlijks gevierde Black Achievement Month. Ook ondersteunt hij scholen bij de verankering van wereldburgerschap in het onderwijs. 


\section{Van een koloniaal naar een meerstemmig perspectief}

In haar boek Witte onschuld (2016) bespreekt Gloria Wekker het 'dominante witte zelfbeeld' in Nederland en hoe het kan dat veel Nederlanders denken dat de bijna vierhonderd jaar waarin Nederland als kolonisator een gigantisch rijk bezat, geen sporen heeft nagelaten in onze hedendaagse maatschappij, in onze instituties, de taal, de manier van denken en handelen, en in de omgang tussen wit en zwart. Ze toont hoe groot de erfenis van koloniale beelden en structuren nog steeds is, wat onder meer zichtbaar wordt in racisme, uitsluitingsmechanismen en in stereotiepe beeldvorming rondom zwarte mensen.

Rondom de trans-Atlantische slavernij zijn rassentheorieën ontwikkeld en gepropageerd waarin witte mensen als superieur werden voorgesteld en zwarte mensen als inferieur (alsof het geen mensen waren). Nederland kende eeuwenlang een dominant discours gebaseerd op deze rassentheorieën. Ook na de afschaffing van de slavernij werkte (en werkt) dit door in bijvoorbeeld de wetenschap, literatuur en beeldvorming.

Dat de dominantie van koloniale structuren en bijbehorende beeldvorming eeuwen heeft bestaan, plaatst de circa 150 jaar dat slavernij is afgeschaft in perspectief. Pas circa 75 jaar na de afschaffing van slavernij volgde de introductie van universele mensenrechten bij de oprichting van de Verenigde Naties rond 1945. Pas circa 50 jaar geleden joegen burgerrechten- en 'black power'-bewegingen antidiscriminatiewetgeving in verschillende landen aan - om slechts enkele ijkpunten te noemen in de ontwikkeling van de rechtspositie van zwarte mensen, internationaal en in dominant witte samenlevingen. Echter, tegenwoordig bestaat structureel racisme tegen zwarte mensen nog steeds, net als structurele ongelijkheid tussen zwarte en witte mensen en een dominant wit perspectief. Ook wordt het bestaan van deze fenomenen regelmatig ontkend.

Het is interessant dat ontwikkelingen rondom erkenning en kritischer kijken naar het eigen slavernijverleden per land sterk verschillen. In Nederland - en ook in andere Europese landen - vinden nu pas ontwikkelingen plaats die overeenkomsten vertonen met ontwikkelingen in de jaren vijftig van de twintigste eeuw in de Verenigde Staten naar aanleiding van de zwarte burgerrechtenbeweging en 'black power', en in de jaren tachtig van de twintigste eeuw in het Verenigd Koninkrijk naar aanleiding van de permanente migratie naar Groot-Brittannië van 'rijksgenoten' uit voormalige Britse koloniën in het Caraïbisch gebied en Afrika (Small, 2012).

In Dagen Van Gejuich En Gejubel geeft Glenn Willemsen (2007) aan dat Nederland in de negentiende eeuw, in tegenstelling tot sommige andere landen, geen groot debat rondom slavernij of een grote antislavernijbeweging kende en dat de transAtlantische slavernij in Nederland ook daarna een 'non issue [is gebleven] in zowel het publieke domein als in het collectieve geheugen' (p. 16). In The Dutch Atlantic - Slavery, Abolition and Emancipation beschrijven Nimako en Willemsen (2012) hoe de geschiedenis van de trans-Atlantische slavernij 'parallelle geschiedenissen' heeft geschapen voor witte en zwarte bevolkingsgroepen en hun nazaten, en hoe witte elites door ongelijke machtsverhoudingen onevenredig hun eigen stempel op geschiedenisbeelden hebben gedrukt. Pas recent participeren 
steeds meer afstammelingen van tot slaaf gemaakte mensen ook aan geschiedschrijving, wat zorgt voor veranderingen in interpretaties en narratieven.

Volgens Nimako en Willemsen is een belangrijke erfenis van het slavernijverleden dat de emancipatie onvoltooid is. Ook bespreken ze vijf belangrijke trends rondom herdenking, herstelbetalingen, officiële excuses, erfgoed en musea, en nieuwe antislavernijbewegingen gericht op hedendaagse slavernij (Nimako \& Willemsen, 2012).

\section{Van 1930 tot nu in Nederland}

In Nederland strijden met name zwarte mensen al decennialang tegen dominante 'witte', koloniale perspectieven op slavernij- en kolonisatiegeschiedenissen en voor erkenning van perspectieven van zwarte mensen. Zo publiceerde Anton de Kom in 1934 zijn boek Wij slaven van Suriname, waarin hij onder meer schrijft:

'Wanneer wij (...) op school les in de Vaderlandse Geschiedenis kregen, dan was dat natuurlijk de geschiedenis der blanke krijgslieden. Voor de klas stonden de eerwaarde Tilburgse broeders en zij onderwezen ons in de heldendaden van Piet Hein en van De Ruiter, Tromp in de Evertsen en Banckert. (...) Wij, die de namen van de opstandelingen Boni, Baron en Joli Coeur tevergeefs in onze geschiedenisboekjes zochten, beijverden ons om vlug en nauwgezet voor het examen de namen en jaartallen op te dreunen der Nederlandse gouverneurs, onder wier bewind men onze vaders als slaven ingevoerd heeft.'

Een ander voorbeeld vinden we in de archieven van Vereniging Ons Suriname. De vereniging gaf in de jaren vijftig het tijdschrift de Koerier uit, onder redactie van Huiswoud, Beeldsnijder, Sarucco en Moll. In 1956 werd hierin onder meer betoogd:

'De koloniale opvoeding (...) is direct gericht tegen de geschiedenis van het volk, historische feiten worden vervalst, de geschiedenis van het volk wordt geheel verdrongen door die van het moederland, of zij wordt domweg "verdonkermaand". Nationale helden worden misdadigers en terroristen, terwijl de kolonialisten gepresenteerd worden als vaderlijke, menslievende, hoger ontwikkelden en soms zelfs tot nationale helden van het gekoloniseerde volk worden verheven.' ('Kolonialisme', 1956)

Uit de archieven van Vereniging Ons Suriname blijkt ook dat Surinamers in Nederland al minstens sinds de jaren vijftig van de twintigste eeuw Keti Koti-herdenkingen organiseren op of rond 1 juli, onder meer binnen de Vereniging Ons Suriname, ter herdenking en viering van de afschaffing van de slavernij. Zo werd in 1963, honderd jaar na de officiële afschaffing van de slavernij op Nederlands grondgebied in 1863, een grote Keti Koti-optocht door de straten van Amsterdam georganiseerd. Daarnaast organiseerde Vereniging Ons Suriname in de jaren vijf- 
tig, zestig en zeventig verschillende 1 juli-manifestaties en evenementen, waaronder in Hotel Krasnapolsky in Amsterdam.

Pas in de jaren negentig slaagden zwarte organisaties erin de herdenking van het slavernijverleden en de viering van Keti Koti in Nederland op de nationale agenda te krijgen (Willemsen, 2007; Wekker, 2016). Vrouwenbeweging Sophiedela en later het Landelijk Platform Slavernijverleden (bestaand uit diverse organisaties van Nederlanders van Surinaamse, Nederlands-Caraïbische en Ghanese afkomst) speelden hierin een centrale rol.

Op de Internationale VN-conferentie tegen Racisme in Durban in Zuid-Afrika in 2001 werd de trans-Atlantische slavernij internationaal als misdaad tegen de menselijkheid erkend. Namens Nederland betuigde toenmalig minister Roger van Boxtel 'diepe spijt' over de Nederlandse slavernij en slavenhandel en gaf aan dat Nederland 'het grote onrecht uit het verleden erkent'. In de aanloop naar deze conferentie was vanuit de Nederlandse regering de toezegging gedaan dat er in Nederland een monument en instituut zouden komen rondom de trans-Atlantische slavernij. In 2002 werd dit Nationaal Monument Slavernijverleden onthuld in het Oosterpark in Amsterdam en werd ook het Nationaal instituut Nederlands Slavernijverleden en erfenis (NiNSee) opgericht. Sindsdien wordt de afschaffing van de slavernij op Nederlands grondgebied op nationaal niveau herdacht en gevierd, waarop ook enkele vieringen op gemeenteniveau volgden. Toch is Keti Koti op nationaal niveau nog steeds overwegend onbekend. Het is geen nationale feestdag, en een deel van de mensen die het wel kennen beschouwt het meer als een herdenking van de 'Surinaamse gemeenschap' dan van de 'Nederlandse'. In 2015 bleek het budget dat de overheid voor de herdenking van de afschaffing van de slavernij in Nederland aan NiNSee ter beschikking stelde ongeveer 130 keer kleiner dan het budget van het Nationaal Comité 4 en 5 mei voor de Nationale Dodenherdenking, Bevrijdingsdag en gerelateerde activiteiten (Eigenraam, Röling \& Venema, 2015). In 2014 trok het tweede kabinet-Rutte met gedoogsteun van de PVV vervolgens de complete structurele financiering voor NiNSee in. Subsidiëring van de Nederlandse nationale slavernijherdenking en andere activiteiten werd vanaf dit moment afhankelijk van individuele aanvragen door NiNSee. Dit zorgde voor verdere verzwakking en onzekerheid rondom de herdenking en NiNSee als organisatie. Via ondersteuning van onder andere de gemeente Amsterdam kon NiNSee in afgeslankte vorm nog enige financiering behouden.

\section{Stappen vooruit}

Via een lange weg is dus inmiddels weliswaar nationale maar fragiele aandacht voor het slavernijverleden bereikt. Meer aandacht voor een onderwerp leidt echter niet noodzakelijkerwijs tot verandering van de mainstreamperspectieven. Dus als we ervan uitgaan dat oude koloniale beeldvorming een grote rol speelt in het momenteel dominante perspectief op het slavernijverleden, dan leidt meer aandacht voor het slavernijverleden niet automatisch tot aanscherping of doorbreking van die eenzijdigheid in de huidige mainstreamperspectieven. Dit geldt zeker 
als de geschiedenis van de trans-Atlantische slavernij geïsoleerde, oppervlakkige en beperkte aandacht krijgt. Daarentegen kan aandacht voor 'zwarte' perspectieven wel leiden tot een meer gebalanceerd geschiedbeeld.

Het is de vraag of er een transitie gaande is van een dominant conservatief, eenzijdig en koloniaal perspectief naar een meer gebalanceerd perspectief gebaseerd op meerstemmigheid. ${ }^{1}$ Relevant hiervoor zijn onder andere ontwikkelingen in de wetenschap, het onderwijs, musea en erfgoedinstellingen, overheden, media en het publieke debat.

Binnen deze gesuggereerde transitie kunnen verschillende stadia gedefinieerd worden, zowel op het niveau van individuen als op het niveau van systemen en op het niveau van de gehele maatschappij, waarbij in elk van deze stadia oude perspectieven door nieuwe worden doorbroken. Het bewustzijn van andere perspectieven kan als een eerste stadium worden gezien, gevolgd door erkenning en acceptatie van deze perspectieven. Hieruit zouden aanscherping van de eigen perspectieven en daadwerkelijke verandering voort moeten komen.

Zoals hierboven besproken, strijden met name zwarte mensen en organisaties al lange tijd voor veranderingen richting een inclusiever of meer meerstemmig perspectief. Mensen, groepen en organisaties die werken aan aandacht en erkenning van zwarte perspectieven lijken momenteel terrein te winnen: ze krijgen meer aandacht en worden meer gehoord. Anderzijds is er ook nog een lange weg te gaan om de doorwerking van koloniale beelden en structuren die honderden jaren gepropageerd en gereproduceerd zijn, te veranderen.

\section{Onderwijs rondom het slavernijverleden}

In 2017 bleek uit een peiling van het tv-programma EenVandaag dat circa 67 procent van de Nederlanders wil dat scholen verplicht onderwijzen over de slavernijgeschiedenis (Vliet e.a., 2017). De manier waarop dit onderwijs vervolgens wordt ingevuld, is daarbij belangrijk. Uit onderzoek van Melissa Weiner uit 2014 bleek dat de informatie over de trans-Atlantische slavernij in Nederlandse schoolboeken nog veelal lijkt geschreven vanuit een wit koloniaal perspectief in plaats van een meerstemmig perspectief waarin ook zwarte perspectieven voldoende aandacht krijgen. Weiner bekeek voor haar onderzoek meer dan tweehonderd schoolboeken die tussen 1980 en 2011 werden gebruikt. Ze concludeerde bijvoorbeeld dat slaafgemaakten als handelswaar werden beschreven, dat acties van verzet tegen de slavernijregimes weinig aandacht kregen en dat de Gouden Eeuw bijna nergens in verband gebracht werd met slavenhandel en gedwongen arbeid van slaafgemaakten (Weiner, 2014).

In het Nederlandse geschiedenisonderwijs neemt momenteel de Canon van Nederland een centrale plaats in. 'Slavernij' is een van de vijftig zogeheten 'vensters' in deze canon, en dus een kernelement. Nog steeds hangt het echter in grote mate af van de docent in hoeverre dit thema wordt verbonden met andere thema's rondom de Gouden Eeuw, waar veel meer aandacht naar uitgaat. In het gehele primair en middelbaar onderwijs wordt momenteel een landelijke curricu- 
lumherziening voorbereid. Het is echter nog onduidelijk welke wijzigingen hieruit zullen volgen.

Ook buiten het onderwijs, in het mainstreamdiscours rondom erfgoed en geschiedbeeld in Nederland, neemt de Gouden Eeuw verbonden aan een positief narratief een dominante plaats in. Hierbij wordt de Gouden Eeuw niet tussen aanhalingstekens geplaatst en kennelijk gezien als een neutrale benaming. Echter, wat vanuit het dominante perspectief een 'gouden eeuw' wordt genoemd, kan vanuit een ander perspectief ook als een 'holocaust' of als een eeuw van uitbuiting op wereldschaal gezien worden. Ook lijkt het mainstreamdiscours weinig aandacht te geven aan racistische beeldvorming en andere anti-zwarte uitsluitingsmechanismen die als een erfenis zijn verbonden aan de trans-Atlantische slavernij. Hieruit kan worden afgeleid dat duiding en het bieden van context rondom de impact van de trans-Atlantische slavernij belangrijk blijven.

\section{Onderzoek naar het slavernijverleden}

Ook binnen de wetenschappelijke geschiedschrijving in Nederland kunnen nog verschillende stappen gezet worden om van een dominant koloniaal perspectief richting meerstemmige perspectieven te bewegen. Hierover is al veel geschreven, onder andere door Waldo Heilbron in De Toekomst van het Verleden, reflecties over Nederland's slavernijverleden en -erfgoed (2006). Over het belang van focus op zwarte perspectieven schrijft hij bijvoorbeeld dat het 'geschiedbeeld en erfgoed m.b.t. het slavernijverleden (...) nog steeds het stempel [dragen] van koloniale vooringenomenheid en daaraan verbonden ideeën van grootsheid van de identiteit van de kolonisator'. Hij betoogt daarom dat

'het zoeklicht gericht [moet] worden op wat destijds de eigen ervaringswereld van de zwarte bevolking in slavernij was, een aspect dat in belangrijke mate buiten beeld is gebleven. (...) De overweging is dat dit slechts op adequate wijze kan, als de geschiedenis van het slavernijverleden opnieuw wordt vormgegeven, gereconstrueerd, waarbij ervaringswereld en gedachtengoed van de mensen in slavernij een belangrijke plaats krijgen.'

Bij het ontsluieren en reconstrueren van de geschiedenis gaat het volgens hem niet om het toevoegen van kennis vanuit 'traditionele perspectieven', maar om:

'het stellen van fundamentele vragen die op de instelling een nieuw licht kunnen doen schijnen, vanuit een meervoudig perspectief. (...) Bij het reconstitueren, het opnieuw vormgeven, is het achterhalen van de koloniale vooringenomenheid noodzakelijk: in de selectie van feiten, de beschrijving en interpretatie.'

Hierbij gaat het volgens Heilbron concreet juist om 'andersoortige vraagstellingen, andersoortige technieken van onderzoek, zelfs een andersoortig woordgebruik, dan die welke het zicht op de toenmalige verhoudingen en bijgevolg ook 
het historisch bewustzijn hebben bepaald'. Daarnaast suggereert hij het gebruik van orale bronnen. Ten slotte vraagt hij zich af of wij 'met de zoektocht naar het Nederlands "verzwegen slavernijverleden" aan de vooravond van een nieuw paradigma' staan.

In de afgelopen jaren is veel onderzoek gepubliceerd met aandacht voor zwarte en meerstemmige perspectieven. In het 'Mapping Slavery'-project bijvoorbeeld komen verschillende vragen samen, waaronder de vraag wie van slavernij in Nederland en zijn koloniën heeft geprofiteerd en welke sporen slavernij en zwarte mensen door de eeuwen heen in Nederland hebben nagelaten (Hondius \& Jouwe, 2014). In 2014 verscheen Gids Slavernijverleden Amsterdam, waarin Dienke Hondius, Nancy Jouwe, Dineke Stam, Jennifer Tosh en Annemarie de Wildt meer dan 100 locaties in Amsterdam laten zien die verbonden zijn met het slavernijverleden van de stad. Recentelijk is van dezelfde auteurs ook de landelijke Gids Slavernijverleden Nederland verschenen (Hondius e.a., 2019). Een van de auteurs, Jennifer Tosh, organiseert daarnaast sinds 2013 met haar organisatie Black Heritage Tours rondleidingen door Amsterdam langs de vele plekken waar het slavernijverleden in Amsterdam nog zichtbaar is. Andere voorbeelden van recente onderzoeken zijn de proefschriften van Ellen Neslo (2016), waarin zij de negentiendeeeuwse zwarte elite in Paramaribo onderzoekt, en van Mano Delea (2019) over panafrikanisme als een erfenis van slavernij. Recent hebben Matthias van Rossum en Karwan Fatah-Black (2012) meer aandacht gevestigd op de economische impact van de Nederlandse trans-Atlantische slavenhandel. Andere voorbeelden betreffen het onderzoek onder leiding van Kwame Nimako bij het NiNSee naar het debat in de Nederlandse Tweede Kamer rondom de afschaffing van de slavernij, en het onderzoek van Mark Ponte (2018) naar Afro-Amsterdammers in de zeventiende eeuw. Verder krijgen nog meer perspectieven aandacht die voorheen weinig aandacht kregen, zoals bijvoorbeeld het onderzoek naar slavernij in voormalig Nederlands-Indië (Baay, 2015; Van Rossum, 2015).

Deze verschuivingen in het wetenschappelijk debat mogen nog wel zichtbaarder worden voor een breed publiek, en daarnaast blijft ook in de wetenschap aandacht voor meerstemmigheid, zwarte perspectieven en de impact van de slavernijgeschiedenis op het heden noodzakelijk.

\section{The Black Archives}

The Black Archives is een voorbeeld van een organisatie die zich inzet voor erkenning en aandacht voor zwarte perspectieven. Met een collectie van duizenden boeken, documenten en objecten geeft en vraagt dit initiatief aandacht voor perspectieven, geschiedenissen en erfgoed van zwarte mensen die elders vaak onderbelicht blijven. ${ }^{2}$ The Black Archives stelt aan de kaak dat de geschiedenis zoals die bijvoorbeeld wordt behandeld in het onderwijs, in de media en het publieke debat en in veel erfgoedinstellingen, witte mensen en het 'Westen' centraal stelt. Een belangrijke doelstelling is de waarde tonen van perspectieven en erfgoed van zwarte mensen, en daarmee het dominante perspectief aanvullen en doorbreken. ${ }^{3}$ 
Om dit doel te bereiken organiseert The Black Archives verschillende inhoudelijke activiteiten rondom haar collecties, zoals exposities, evenementen, rondleidingen, workshops en samenwerkingen. Verder tracht het verschillende kennislacunes te dichten. Zo worden voorbeelden van racistische beelden en karikaturen van zwarte mensen getoond die hun oorsprong hebben in rassentheorieën ten tijde van de slavernij en in moderne populaire cultuur terecht zijn gekomen, zodat bezoekers de link kunnen leggen tussen de geschiedenis van rassentheorieën ten tijde van de slavernij en racisme op verschillende niveaus vandaag. Daarnaast adresseert The Black Archives de geschiedenis van Keti Koti op 1 juli, de dag dat we in Nederland de afschaffing van de slavernij vieren. Duidelijk wordt gemaakt dat slavernij op Nederlands grondgebied weliswaar officieel werd afgeschaft in 1863, maar dat de tot slaaf gemaakte mensen daarna nog tien jaar gedwongen door moesten werken onder vergelijkbare omstandigheden (de 'Staatstoezicht'periode).

Ook worden 'wisselbrieven' getoond, documenten die bij de afschaffing van de slavernij door de Nederlandse overheid werden uitgegeven. Dit waren tegemoetkomingen in geld, echter niet bestemd voor de mensen die vanuit slavernij 'vrij' werden, maar voor de 'slavenhouders', omdat een deel van hun 'bezit' werd afgenomen. De Nederlandse overheid besteedde gigantische bedragen aan deze tegemoetkomingen. ${ }^{4}$ En hierop volgde nog meer beleid dat de tot slaaf gemaakten en hun nakomelingen achterstelde en dat niet-zwarte groepen bevoordeelde, vanaf de afschaffing van de slavernij tot aan het heden.

The Black Archives maakt met haar collecties de geschiedenis van racisme zichtbaar in Nederland en het verzet en activisme hiertegen. Eind 2017 opende de tentoonstelling Zwart en Revolutionair: het verhaal van Hermina en Otto Huiswoud, over de geschiedenis en erfenis van dit revolutionaire koppel. Daarna volgde de expo Onze * Tori: Verhalen van Surinamers in Nederland, vooruitlopend op een nieuwe expositie over het 100-jarige bestaan van Vereniging Ons Suriname in 2019. Daarnaast publiceerde The Black Archives samen met De Correspondent en FunX verschillende artikelen en verhalen rondom het thema 'Verzwegen Geschiedenis'. Met lesmateriaalontwikkeling en rondleidingen voor leerlingen, studenten en docenten richt The Black Archives zich verder expliciet op veranderingen in het onderwijs.

\section{Beleid}

De transitie naar een meerstemmig en meer gebalanceerd perspectief kan worden versneld als invloedrijke mensen, organisaties, overheden en andere actoren hun nek uitsteken om de personen, initiatieven en organisaties die opkomen voor meer balans en een betere representatie van zwarte perspectieven te versterken. Wie aan versnelling van de transitie wil bijdragen, benadert deze personen, initiatieven en organisaties proactief, stelt zich open voor hun feedback en werkt op gelijkwaardig niveau met hen samen. 


\section{Noten}

1 Inzichten uit de transitiekunde kunnen mogelijk handvatten bieden voor verdere analyse. Hierbij wordt uitgegaan van het aanjagen van veranderingen door 'veranderaars' vanuit de samenleving in wisselwerking met facilitering en beantwoording door overheden en andere actoren met een grote impact op systeemverandering. Zie bijvoorbeeld Rotmans, 2012.

2 Waldo Heilbrons persoonlijke boekencollectie, die duizenden boeken omvatte, vormde de startcollectie van The Black Archives.

3 The Black Archives is in 2015 opgericht door Jessica de Abreu, Mitchell Esajas, Thiemo Heilbron en de auteur van dit artikel en samen met anderen verder ontwikkeld. De organisatie wordt gedragen door New Urban Collective. Zie ook http://www. theblackarchives.nl/over-ons.html, geraadpleegd op 29 maart 2019.

4 De Nederlandse regering betaalde aan eigenaren per tot slaaf gemaakt persoon circa 300 gulden in Suriname en circa 200 gulden op de verschillende eilanden. In totaal bedroeg de tegemoetkoming ongeveer 12 miljoen gulden, circa 10 procent van de totale rijksuitgaven van de Nederlandse staat in 1863. Zie ook www.cbs.nl/nl-nl/ achtergrond/2013/27/op-1-juli-1863-47-duizend-slaven-vrijgemaakt-in-suriname-enop-de-antillen, geraadpleegd op 29 maart 2019.

\section{Literatuur}

Baay, R. 2015. 'Daar werd wat gruwelijks verricht, Slavernij in Nederlands-Indië'. Amsterdam: Atheneaeum - Polak \& van Gennep.

Delea, M. (2019). Pan-Africanism: A Legacy of Slavery (proefschrift).

Eigenraam, A., Röling, D., \& Venema, N. (2015, 20 maart). Frustrerend dat slavernijherdenkers telkens om subsidie moeten bedelen. De Volkskrant. www.nrc.nl/nieuws/ 2015/03/20/frustrerend-dat-slavernijherdenkers-telkens-om-subsidie-moetenbedelen-a1406055. Geraadpleegd op 29 maart 2019.

Heilbron, W. (2006). De Toekomst van het Verleden, reflecties over Nederland's slavernijverleden en -erfgoed. Amsterdam: Museum Suriname.

Hondius, D., \& Jouwe, N. (2014). Mapping Slavery.https://mappingslavery.nl/over-ons/. Geraadpleegd op 29 maart 2019.

Hondius, D., Jouwe, N., Stam, D., Tosh, J., \& Wildt, A. de (2014). Gids slavernijverleden Amsterdam. Volendam: LM Publishers.

Hondius, D., Jouwe, N., Stam, D., Tosh, J., \& Wildt, A. de (2019). Gids Slavernijverleden Nederland. Volendam: LM Publishers.

Kolonialisme (1956). In: O. Huiswoud, R. Beeldsnijder, W.A. Sarucco \& M. Moll (red.), De Koerier, orgaan van de werkcommissie Ver. 'Ons Suriname', 3 (1): 2-3.

Kom, A. de (1934). Wij slaven van Suriname. Amsterdam: Uitgevers-mij. Contact.

Neslo, E. (2016). Een ongekende elite. Utrecht: Haes Producties.

Nimako, K., \& Willemsen, G. (2012). The Dutch Atlantic - Slavery, Abolition and Emancipation. Londen: Pluto Press.

Ponte, M. (2018). 'Al de swarten die hier ter stede comen.' Een Afro-Atlantische gemeenschap in zeventiende-eeuws Amsterdam. TSEG/Low Countries Journal of Social and Economic History, 15 (4): 33-62. 
Rossum, M. van (2015). Kleurrijke tragiek. De geschiedenis van slavernij in Azië onder de VOC. Hilversum: Verloren.

Rossum, M. van, \& Fatah-Black, K. (2012). Wat is winst? De economische impact van de Nederlandse trans-Atlantische slavenhandel. TSEG/Low Countries Journal of Social and Economic History, 9 (1): 3-29.

Rotmans, J. (2012). In het oog van de orkaan. Boxtel: Aeneas.

Small, S. (2012). Foreword. In: K. Nimako \& G. Willemsen (red.), The Dutch Atlantic - Slavery, Abolition and Emancipation. Londen: Pluto Press.

Vliet, L. van, Rademaker, G., Nagtzaam, P., \& Schram P. (red.) (2017). Peiling: Meerderheid voor verplichte Wilhelmus-les. Eenvandaag, 16 augustus. https://eenvandaag.avrotros. $\mathrm{nl} /$ panels/opiniepanel/alle-uitslagen/item/peiling-meerderheid-voor-verplichtewilhelmus-les/. Geraadpleegd op 29 maart 2019.

Weiner, M. (2014). Racial Neoliberalism, Social Forgetting, and Scientific Colonialism in Dutch Primary School History Textbooks. (E)RACING SLAVERY, 11 (2).

Wekker, G. (2016). Witte onschuld. Paradoxen van kolonialisme en ras. Amsterdam: Amsterdam University Press.

Willemsen, G. (2007). Dagen Van Gejuich En Gejubel. Amsterdam: Amrit. 